\title{
Reconsolidation or Extinction: Transcription Factor Switch in the Determination of Memory Course after Retrieval
}

\author{
Verónica de la Fuente, Ramiro Freudenthal, and Arturo Romano \\ Laboratorio de Neurobiología de la Memoria, Departamento de Fisiología, Biología Molecular y Celular, Facultad de Ciencias Exactas y Naturales, \\ Universidad de Buenos Aires, Instituto de Fisiología, Biología Molecular y Neurociencias, Consejo Nacional de Investigaciones Científicas y Técnicas, \\ Ciudad Universitaria, 1428 EHA Buenos Aires, Argentina
}

In fear conditioning, aversive stimuli are readily associated with contextual features. A brief reexposure to the training context causes fear memory reconsolidation, whereas a prolonged reexposure induces memory extinction. The regulation of hippocampal gene expression plays a key role in contextual memory consolidation and reconsolidation. However, the mechanisms that determine whether memory will reconsolidate or extinguish are not known. Here, we demonstrate opposing roles for two evolutionarily related transcription factors in the mouse hippocampus. We found that nuclear factor $-\kappa \mathrm{B}(\mathrm{NF}-\kappa \mathrm{B})$ is required for fear memory reconsolidation. Conversely, calcineurin phosphatase inhibited NF- $\kappa$ B and induced nuclear factor of activated T-cells (NFAT) nuclear translocation in the transition between reconsolidation and extinction. Accordingly, the hippocampal inhibition of both calcineurin and NFAT independently impaired memory extinction, whereas inhibition of NF- $\kappa \mathrm{B}$ enhanced memory extinction. These findings represent the first insight into the molecular mechanisms that determine memory reprocessing after retrieval, supporting a transcriptional switch that directs memory toward reconsolidation or extinction. The precise molecular characterization of postretrieval processes has potential importance to the development of therapeutic strategies for fear memory disorders.

\section{Introduction}

In contextual associative memories, retrieval induced by reexposure to the training context without reinforcement may generate one of two apparently competing processes, reconsolidation or extinction. Once reactivated by a brief reexposure, memory becomes labile and requires reconsolidation, a process mechanistically similar to consolidation, to restabilize it in a long-term form (Dudai and Eisenberg, 2004; Nader et al., 2000). The activation of transcription factors, such as cAMP response element-binding protein (CREB), activator protein 1 (AP-1), zinc fingers inducing factor 268 (Zif268), and nuclear factor- $\kappa \mathrm{B}(\mathrm{NF}-\kappa \mathrm{B})$, and the resulting changes in gene expression during discrete time periods after learning are key processes in consolidation (Alberini, 2009). It was found that reconsolidation also requires regulation of the gene expression (Merlo et al., 2005; Boccia et al., 2007; Lubin and Sweatt, 2007; Mamiya et al., 2009). In contrast to reconsolidation, prolonged reexposure to the training context induces extinction. A body of evidence supports that the original memory is not canceled by extinction, but its expression is temporarily inhibited, returning spontaneously after a period of time (Rescorla,

\footnotetext{
Received Nov. 19, 2010; accepted Dec. 18, 2010.

This work was supported by Agencia Nacional de Promoción Científica y Tecnológica Grants PICT 26095 and PICT 2049, and Secretaría de Ciencia y Técnica de la Universidad de Buenos Aires Grant X193. We especially thank Dr. M. E. Pedreira for critical reading of this manuscript, Dr. Liliana Orelli for language correction, and Angel Vidal for technical assistance.

Correspondence should be addressed to Arturo Romano, Departamento de Fisiología, Biología Molecular y Celular, Facultad de Ciencias Exactas y Naturales, Universidad de Buenos Aires, Ciudad Universitaria, Pabellón 2, 2do. Piso (1428 EHA) Buenos Aires, Argentina. E-mail: aromano@fbmc.fcen.uba.ar.

DOI:10.1523/JNEUROSCI.6066-10.2011

Copyright $\odot 2011$ the authors $\quad 0270-6474 / 11 / 315562-12 \$ 15.00 / 0$
}

2004). The fact that extinction memory requires protein synthesis during a defined time window during and/or after induction led to the assumption that it is a new memory that consolidates as the original one. Some experimental data suggest that extinction consolidation requires transcription as well (Lin et al., 2003b; Vianna et al., 2003; Mamiya et al., 2009). However, the temporary nature of the behavioral expression of extinction points to mechanistic differences with the original memory consolidation. In fact, recent studies support distinct molecular requirements, such as the participation of protein phosphatases (Genoux et al., 2002) and endocannabinoids (Marsicano et al., 2002; Suzuki et al., 2004) in the consolidation of extinction, but not in the consolidation of the original memory. The transcription factor $\mathrm{NF}-\kappa \mathrm{B}$ plays a key role in long-term memory consolidation (Freudenthal and Romano, 2000; Meffert et al., 2003; Romano et al., 2006) and reconsolidation (Merlo et al., 2005; Boccia et al., 2007), whereas it is inhibited during extinction induction in crabs (Merlo and Romano, 2008). In contrast, little is known about the role of the transcription factor of activated T-cells [nuclear factor of activated T-cells (NFAT)] in the brain, albeit the way of NFAT activation by calcineurin has been deeply studied in other systems (i.e., immunology). It has been shown previously that NFAT downstream regulation is controlled in cortical or hippocampal neurons by the L-type voltage-gated calcium channels, basal NMDA-type glutamate receptor (NMDAR) activity, and BDNF (Graef et al., 1999; Groth and Mermelstein, 2003), and that it also acts as a mediator of antiapoptotic transcription in NMDA receptor-stimulated cortical neurons (Vashishta et al., 2009). No studies have been made on its role in learning and memory, although its presence in neurons and its activation by $\mathrm{Ca}^{2+} / \mathrm{CaM}$ 
(calmodulin) signal through NMDAR suggest a possible role in neural plasticity and memory.

In contextual fear memory, there is evidence supporting gene transcription during long-term memory extinction in amygdala and prefrontal cortex, but not in the hippocampus, suggesting that gene expression in the latter structure may not be involved (Mamiya et al., 2009). Thus, the participation of transcription factors in the consolidation of extinction is controversial and the role of hippocampus in extinction is not well understood (Lattal et al., 2006). Furthermore, the mechanisms that determine whether a reactivated memory will reconsolidate or extinguish are unknown. The study of the molecular mechanisms involved in the point of decision between these two competing processes is crucial, so as to understand the dynamic of memory after reactivation.

In the present paper, we study the role of two related transcription factors, NF- $\kappa \mathrm{B}$ and NFAT, as well as the $\mathrm{Ca}^{2+}$ / calmodulin-dependent phosphatase $2 \mathrm{~B}$ [calcineurin $(\mathrm{CaN})]$, in hippocampus during mouse fear memory reconsolidation and extinction. These findings support a transcriptional switch that directs memory reprocessing, either toward reconsolidation or extinction.

\section{Materials and Methods}

Animals. C57BL/6 male mice, 60-70 d of age, weighting 25-30 g, were used (La Plata University Animal Facilities, La Plata, Argentina). The animals were individually caged and singly housed throughout the experimental procedures, with water and food ad libitum, under a $12 \mathrm{~h}$ light/dark cycle (lights on at 8:00 A.M.) at a temperature of $21-22^{\circ} \mathrm{C}$. Experiments were performed in accordance with local regulations and the National Institutes of Health (NIH) Guide for the Care and Use of Laboratory Animals (NIH publication 80-23/96). All efforts were made to minimize animal suffering and to reduce the number of animals used.

Surgery and injections. Mice were implanted under deep anesthesia (ketamine and xylazine) with 23 gauge guide cannulae $1 \mathrm{~mm}$ dorsally to the dorsal hippocampus, at coordinates of anterior, -1.9 ; lateral, \pm 1.2 ; and ventral, 1.2, in accordance with the atlas of Franklin and Paxinos (2001). Guide cannulae were fixed to the skull with dental acrylic. Experiments were performed after animal recovery and injections were administered immediately before or after context reexposure (see Results) without anesthesia. The injection device consisted of a 30 gauge cannula connected to a $5 \mu \mathrm{l}$ Hamilton syringe with tubing. Initially, the infusion device was filled with distilled water and a small air bubble was sucked into the injection cannula, followed by the injection solution. The air bubble allowed for visual inspection of the injection progress. The injection cannula was inserted into the guide cannula with its tip extending beyond the guide by $1 \mathrm{~mm}$ to reach the dorsal hippocampus. The injections were administered during $30 \mathrm{~s}$ and operated by hand. The injection cannula was removed after $60 \mathrm{~s}$ to avoid reflux and to allow the diffusion of drugs. The volume of each intrahippocampal infusion was $0.5 \mu /$ side. Different injection devices were used for drug and vehicle. After behavioral procedures, the animals were injected with black ink and were decapitated. The brains were placed in $4 \%$ paraformaldehyde for $1 \mathrm{~d}$ followed by $30 \%$ sucrose for an additional $24 \mathrm{~h}$. To verify cannulae placement, frozen brains were sliced using a cryostat and analyzed with a magnifying glass. The deepest position of the needle was superimposed on serial coronal maps. Only data from animals with cannulae located in the intended sites were included in the analysis.

Drugs. NF- $\kappa$ B Decoy (double-stranded DNA oligonucleotide $5^{\prime}$ GAGGGGACTTTCCCA- $3^{\prime}$; consensus sequence in bold) and mDecoy (5'GAGGCGACTTTCCCA-3'; base changed underlined) (Albensi and Mattson, 2000) were dissolved in STE solution. Decoy or mDecoy were used at a concentration of $0.47 \mu \mathrm{g} / \mu \mathrm{l}$ and delivered $0.26 \mathrm{pmol}$ per side (Freudenthal et al., 2005; Boccia et al., 2007). $3 S-\left[3 R^{\star}\left[E\left(1 S^{*}\right.\right.\right.$, $\left.\left.3 S^{\star}, 4 S^{\star}\right)\right], 4 S^{\star}, 5 R^{\star}, 8 S^{\star}, 9 E, 12 R^{\star}, 14 R^{\star}, 15 S^{\star}, 16 R^{\star}, 18 S^{\star}, 19 S^{\star}, 26 \mathrm{a} R^{\star}-5,6$, $8,11,12,13,14,15,16,17,18,19,24,25,26,26 a-H e x a d e c a h y d r o-5,19$-dihydroxy-3-[2-(4-hydroxy-3-methoxycyclohexyl)-1-methylethenyl]-14,
16-dimethoxy-4,10,12,18-tetramethyl-8-(2-propenyl)-15,19-epoxy-3Hpyrido[2,1-c] [1,4] oxaazacyclotricosine-1,7,20,21(4H,23H)-tetrone, monohydrate [FK-506 (FK)] (Sigma-Aldrich), was administered at a concentration of $10 \mu \mathrm{g} / \mu \mathrm{l}$, diluted in DMSO to deliver $6.22 \mathrm{nmol}$ per side. 11R-VIVIT cell-permeable peptide (NFAT inhibitor; Calbiochem) was used at a concentration of $0.9 \mu \mathrm{g} / \mu \mathrm{l}$ diluted in DMSO to deliver $0.125 \mathrm{nmol}$ per side. All drugs were administered bilaterally in the hippocampus at $0.5 \mu \mathrm{l}$ per side.

Apparatus and behavioral procedures. The conditioning chamber (context A) was made of transparent acrylic $(24.5 \times 24.5 \times 42 \mathrm{~cm})$ in a wooden box with a clear front lid. The floor of the chamber consisted of parallel stainless-steel grid bars, each measuring $0.3 \mathrm{~mm}$ in diameter and spaced $0.8 \mathrm{~mm}$ apart. The grid was connected to a device to deliver the footshocks and tone presentations. Before training, the animals were handled once a day for $2 \mathrm{~d}$. Training consisted of placing the mouse in the chamber (context A) and allowing a 2 min acclimatization period. After this period, the mice received three trials (with an intertrial interval of 1 $\min )$ of a tone presentation $(10 \mathrm{~s}, 80 \mathrm{~dB})$, which coterminated with a footshock $(0.6 \mathrm{~mA}, 1 \mathrm{~s})$. The mice remained in the chamber for an additional minute and were returned to their home cages. Contextual fear conditioning during the test session was evaluated 2,8 , and $15 \mathrm{~d}$ after training by placing the mice in the training environment for $5 \mathrm{~min}$ in the absence of the footshock and the tone. In all experiments, the animals were also tested to the tone (cued fear conditioning) $1 \mathrm{~d}$ after the first contextual test, day 4 . This test was performed by presenting the same tone used in training session, but in a modified chamber (context B). Most of the contextual cues present in the training context were changed (white floor, semicircular green walls, vanilla odor, different chamber and room light intensity, and absence of background noise). The tone was presented for $4 \mathrm{~min}$ after a baseline period of $2 \mathrm{~min}$ to evaluate pretone freezing. Each test was videotaped to calculate freezing.

Memory was assessed and expressed as the percentage of time that the mice spent freezing, which is commonly used as an index of fear in mice. Freezing was defined as the absence of all movements except those related to breathing. Freezing was scored according to an instantaneous timesampling procedure in which each animal was observed every $5 \mathrm{~s}$ in a $300 \mathrm{~s}$ testing period in the case of contextual test (60 measures). In the case of cued test, freezing was evaluated every $5 \mathrm{~s}$ in both pretone period (120 s) and tone period (240 s).

Nuclear and cytosolic extracts. The mice were killed by cervical dislocation at different intervals after context reexposure (see Results). The brains were rapidly removed, and both hippocampi were dissected according to the method of Glowinski and Iversen (1966). To obtain nuclear extracts, tissues were homogenized in $250 \mu \mathrm{l}$ of buffer A (10 mM HEPES, pH 7.9, $10 \mathrm{~mm} \mathrm{KCl}, 1.5 \mathrm{~mm} \mathrm{MgCl}_{2}, 1 \mathrm{~mm}$ DTT, $1 \mu \mathrm{g} / \mathrm{ml}$ pepstatin A, $10 \mu \mathrm{g} / \mathrm{ml}$ leupeptin, $0.5 \mathrm{~mm}$ PMSF, and $10 \mu \mathrm{g} / \mathrm{ml}$ aprotinin) with eight strokes in a Dounce homogenizer, type B pestle. The homogenate was centrifuged for $15 \mathrm{~min}$ at $1000 \times \mathrm{g}$. The supernatant (cytosolic extract) was kept at $-80^{\circ} \mathrm{C}$ until used. The pellet was resuspended in $30 \mu \mathrm{l}$ of buffer B (20 mм HEPES, pH 7.9, $800 \mathrm{~mm} \mathrm{KCl,} 1.5 \mathrm{~mm} \mathrm{MgCl}_{2}, 0.4 \mathrm{~mm}$ EDTA, $0.5 \mathrm{~mm}$ DTT, $50 \%$ glycerol, $1 \mu \mathrm{g} / \mathrm{ml}$ pepstatin A, $10 \mu \mathrm{g} / \mathrm{ml} \mathrm{leu-}$ peptin, $0.5 \mathrm{~mm}$ PMSF, and $10 \mu \mathrm{g} / \mathrm{ml}$ aprotinin) and incubated for $20 \mathrm{~min}$ on ice. A centrifugation for $15 \mathrm{~min}$ at $12,000 \times g$ was then performed. The supernatant (nuclear extract) was stored at $-80^{\circ} \mathrm{C}$ until used. The entire extraction protocol was performed at $4^{\circ} \mathrm{C}$.

Determination of DNA-binding activity by gel shift assay. DNA binding activity of NF- $\kappa \mathrm{B}$ in nuclear fractions was assessed using gel shift assays [electrophoretic mobility shift assay (EMSA)]. An aliquot of $1.75 \mathrm{pmol}$ of double-stranded DNA oligonucleotide containing the NF- $\kappa$ B binding site ( $5^{\prime}$-AGTTGAGGGGACTTTCCCAGGC-3'; binding site in bold) (Promega) was labeled at $37^{\circ} \mathrm{C}$ for $10 \mathrm{~min}$ in $10 \mu \mathrm{l}$ of reaction buffer containing $70 \mathrm{~mm}$ Tris- $\mathrm{HCl}, 10 \mathrm{~mm} \mathrm{MgCl}_{2}, 5 \mathrm{~mm}$ DTT, $15 \mu \mathrm{Ci}$ of $[\gamma$ ${ }^{32}$ P]ATP (PerkinElmer Life and Analytical Sciences) and $10 \mathrm{U}$ of T4 polynucleotide kinase (Promega). DNA-protein binding was performed in $20 \mu \mathrm{l}$ containing $20 \mathrm{~mm}$ HEPES, pH 7.9, $120 \mathrm{~mm} \mathrm{KCl,} 0.4 \mathrm{~mm}$ EDTA, $0.5 \mathrm{~mm}$ DTT, $25 \%$ glycerol, and $10 \mu \mathrm{g}$ of protein extract. The samples were incubated for $40 \mathrm{~min}$ at $0^{\circ} \mathrm{C}$ and $1 \mathrm{ng}$ of labeled oligonucleotide DNA probe was added followed by incubation for another $40 \mathrm{~min}$ at $0^{\circ} \mathrm{C}$. The reaction mixture was then electrophoresed on a $6 \%$ non-denaturing 
polyacrylamide gel in $0.25 \%$ TBE (22.3 mM Tris, $22.3 \mathrm{~mm}$ boric acid, 0.5 mM EDTA) for $2 \mathrm{~h}$ at $160 \mathrm{~V}$. The gel was vacuum-dried and exposed overnight to XAR-5 film (Kodak). The relative optical density (ROD) of the first band corresponding to p65/p50 heterodimer was estimated using NIH ImageJ 1.29 software. All measurements were made with exposures within the linear range of the film. The images were digitized by means of a transmissive scanner (Umax PowerLook III). Protein contents of the extracts were measured in triplicate by Bradford method and checked for quality and quantity by comparing pattern intensities in SDS-PAGE. For supershift assay, p65 antibody was used (Santa Cruz Biotechnology; sc-372).

Western blots. For Western blot assay, loading buffer was added to the samples that were incubated at $100^{\circ} \mathrm{C}$ for $5 \mathrm{~min}$ and immediately placed on ice. Twenty micrograms of each protein sample were run on SDSPAGE with $7.5 \%$ acrylamide in the resolving phase. The proteins were then electrotransferred to polyvinylidene difluoride membrane for immunoblotting. Western blot assays were performed with anti-CaN (Cell Signaling; 7-067; at 1:2000 dilution) and anti-NFATc4 (Santa Cruz Biotechnology; sc-13036; at 1:1000 dilution) antibodies, following the manufacturer's protocol. The cytosolic housekeeping anti-actin (Santa Cruz Biotechnology; sc-6627; at 1:1000 dilution) antibody and the nuclear housekeeping anti-lamin B antibody (Santa Cruz Biotechnology; sc6217; at 1:500 dilution) were used. Detection was made with Luminol chemiluminescence kit (Santa Cruz Biotechnology) as described by the manufacturer and the signals were digitalized by FUJIFILM-Intelligent Dark Box II apparatus with image reader LAS-1000 software. The ROD was estimated using ImageJ 1.29x software. Protein contents of the extracts were measured in triplicate by the Bradford method.

Histology. Fluoresceinated Decoy was injected into hippocampus at the same concentration as in behavioral experiments. Animals were immediately perfused, first with saline, and then with $4 \%$ paraformaldehyde. Brains were dissected and remained in PFA (4\%) for 2-3 more hours. Twenty-four hour passages to reach a $30 \%$ sucrose-PBS concentration were made. Tissues were sectioned at $25 \mu \mathrm{m}$ thickness with a cryostat, stained with propidium iodide, and analyzed by confocal microscopy. Slices stained with cresyl violet show the cannula position.

Data analyses. Behavioral data were analyzed by one-way ANOVA, followed by Newman-Keuls multiple-comparisons post hoc test, comparing the values of the percentages of freezing. When cued fear memory or intrasession extinction was assessed, behavioral data were analyzed by two-way ANOVA, followed by Bonferroni's post hoc test. Gel shift and Western blot data were analyzed by unpaired two-tailed Student's $t$ test between experimental and naive groups, except those experiments in which three groups were used. In this case, one-way ANOVA was performed.

\section{Results}

\section{NF- $\kappa$ B inhibition in the hippocampus impairs fear memory reconsolidation}

Once new associative learning is consolidated, a reminder can induce memory reactivation and reconsolidation (Pedreira and Maldonado, 2003; Suzuki et al., 2004). The process of reconsolidation is required for restabilization of the original memory trace. Some experimental evidence suggests that the activation of transcription factors is necessary for reconsolidation (Miller and Marshall, 2005; Milekic et al., 2007), particularly in the hippocampus, for contextual memories (Kida et al., 2002; Lee et al., 2004). NF- $\kappa \mathrm{B}$ transcription factor is involved in consolidation and reconsolidation in different memory models both in vertebrates and invertebrates (Romano et al., 2006; Boccia et al., 2007; Lubin and Sweatt, 2007). Although the role of NF- $\kappa$ B has already been studied in reconsolidation of memory in mice, it was important to validate those previous results in our behavioral paradigm, to gain additional insight into the molecular mechanisms involved differentially in both extinction and reconsolidation.

In the first experiment, we tested whether, in fear conditioning, the inhibition of NF- $\kappa \mathrm{B}$ in hippocampus impairs long-term memory reconsolidation. Double-stranded DNA oligonucleotide containing the consensus sequence of NF- $\kappa$ B (Decoy) was used as a specific inhibitor (Albensi and Mattson, 2000). This oligonucleotide enters the cells (Fig. $1 a$ ) and induces NF- $\kappa \mathrm{B}$ inhibition 15 min after intrahippocampal injection (Freudenthal et al., 2005; Boccia et al., 2007). A mutated Decoy oligonucleotide (mDecoy) was used as a control for the nonspecific actions of DNA administration in the hippocampus. mDecoy is a stringent control because the entire overall composition of bases is conserved, except for one base in the consensus sequence that is mutated, impeding NF- $\kappa$ B binding (Boccia et al., 2007). The experimental design is presented in Figure $1 b$. On the first day, three groups of animals were placed in the training chamber (context A), and, after 2 min of adaptation, three trials of tone/footshock were presented. On the second day, mice from two of the three groups were reexposed to the training chamber for $5 \mathrm{~min}$ without tone or shock stimulation, and were removed and injected either with Decoy (R-Decoy group) or mDecoy ( $\mathrm{R}-\mathrm{mDecoy}$ group). During reexposure, the percentage of freezing was determined. The third group was not reexposed but was injected with Decoy (NoR-Decoy group). On the third day, all groups were tested for contextual fear memory. The contextual test always consisted of mouse reexposure to the training context for 5 min during which the percentage of freezing was measured. On the fourth day, all groups were tested for cued fear memory. Each mouse was placed in a modified chamber (context B), and after 2 min of baseline the same tone used in training was presented for $4 \mathrm{~min}$. Both pretone and during-tone freezing were assessed. Additional contextual tests were performed 1 and 2 weeks after injection. During reexposure (Fig. $1 c$, day 2), R-Decoy and R-mDecoy groups showed normal freezing responses. In the first contextual test (Fig. 1c, day 3 ), similar levels of freezing were observed between NoR-Decoy and R-mDecoy groups. However, a significantly lower level of freezing was observed in the R-Decoy group (ANOVA: $F_{(2,24)}=$ 3.550, $p<0.05$; Newman-Keuls post hoc test, NoR-Decoy vs $\mathrm{R}$-Decoy, $p<0.05$, and R-mDecoy vs R-Decoy, $p<0.05)$, indicating that only when animals were reexposed to the training context, Decoy, but not mDecoy, induced memory impairment. Similar results were found in the subsequent contextual tests 1 week (Fig. 1c) (ANOVA: $F_{(2,25)}=3.497, p<0.05$; NewmanKeuls post hoc test: NoR-Decoy vs R-Decoy, $p<0.05$, and R-mDecoy vs R-Decoy, $p<0.05$ ) and 2 weeks after injection (Fig. 1c) (ANOVA: $F_{(2,25)}=3.446, p<0.05$; Newman-Keuls post hoc test: R-mDecoy vs R-Decoy, $p<0.05)$. A test for cued conditioning was performed using the same animals at day 4 . Mice were placed in the context B and freezing was measured. Pretone freezing was low for the three groups, and after tone presentation, freezing was similarly higher for all groups (Fig. $1 d$ ), indicating that freezing to tone was not affected by hippocampal Decoy injection (repeated-measures two-way ANOVA: main effect of time: $F_{(1,25)}=83.09, p<0.0001$; main effect of group: $F_{(2,25)}=$ $0.9893, p=0.3885$; interaction: $F_{(2,25)}=1.714, p=0.2043$; Bonferroni's post hoc test between pretone and tone: NoR-Decoy, $p<$ 0.01 ; R-mDecoy, $p<0.001$; R-Decoy, $p<0.001)$. This result is expected considering that cued fear conditioning is independent of the hippocampus (Phillips and LeDoux, 1992) and thus is a control test for specific NF- $\kappa$ B inhibition in that brain area. Another experiment was performed in which short-term reactivated memory (STRM) was tested $4 \mathrm{~h}$ after reexposure (Fig. 1e). As expected (Nader et al., 2000), the R-Decoy group showed normal levels of freezing at the $4 \mathrm{~h}$ test but low levels of freezing at the $24 \mathrm{~h}$ test (Fig. 1c,f), indicating that STRM was not affected by treatment with the Decoy. To test whether Decoy administration pro- 
a
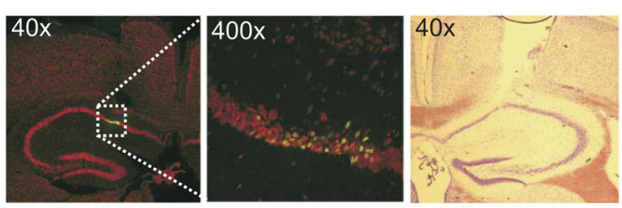

b
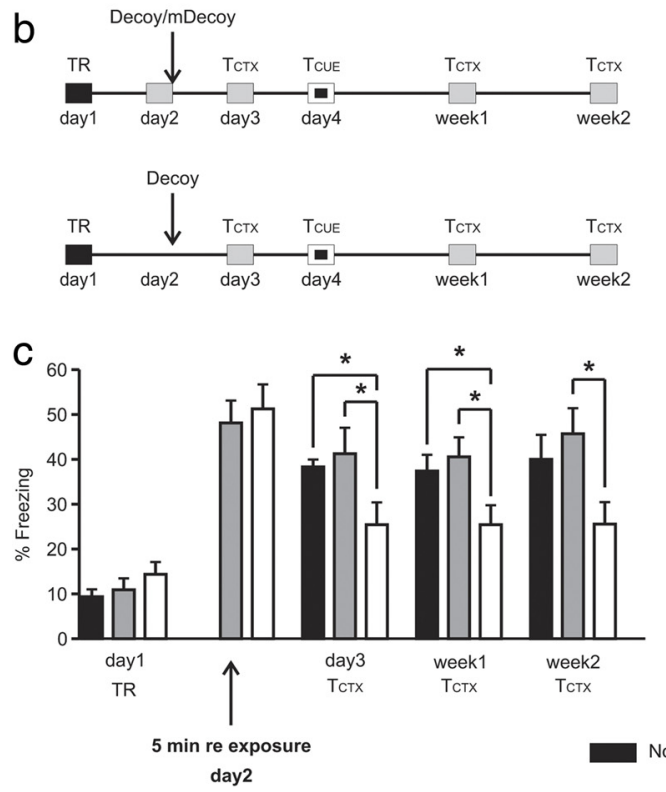

e
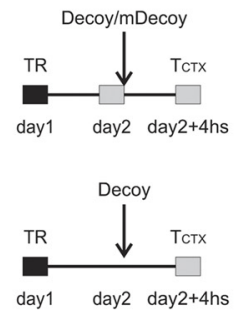

f

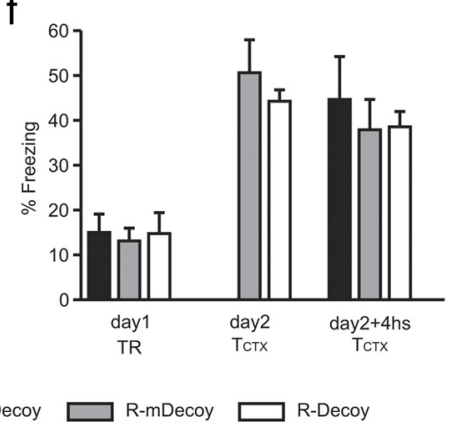

Figure 1. NF- $\kappa B$ inhibition in the hippocampus impairs contextual fear memory reconsolidation. Data are expressed as mean \pm SEM of freezing response. $\boldsymbol{a}$, Confocal micrographs show distribution of fluoresceinated Decoy (green) 5 min after hippocampal injection, contrasted with propidium iodide. Concentration was the same of the nonfluoresceinated Decoy used in pharmacological experiments. An image showing an example of cannula position is also shown (cresyl violet stained). $\boldsymbol{b}$, Design of the experiment shown in c. All groups were trained at day 1; at day 2, animals were either reexposed for 5 min to the training context and injected with mDecoy (R-mDecoy) $(n=9)$ or with Decoy (R-Decoy) $(n=8)$, or were non-reexposed and injected with Decoy (NoR-Decoy) $(n=8)$. TR, Training session; Tctx, contextual test; Tcue, cued test. c, Effect of hippocampal NF- $\kappa B$ inhibition in contextual memory reconsolidation. $\boldsymbol{d}$, Effect of hippocampal NF- $\kappa$ B inhibition in cued memory. Groups and animals are as in $\boldsymbol{b}$. $\boldsymbol{e}$, Design of the experiment shown in $\boldsymbol{f}$. Animals were trained, reexposed or non-reexposed, and injected either with mDecoy or Decoy as in $\boldsymbol{b}$, but the contextual test was performed $4 \mathrm{~h}$ after reexposure $(24 \mathrm{~h}$ plus $4 \mathrm{~h}$ from TR in the case of the non-reexposed group). $\boldsymbol{f}$, Effect of NF- $\kappa$ B inhibition in contextual STRM; NoR-Decoy, $n=6$; R-mDecoy, $n=8$; R-Decoy, $n=7$. ${ }^{*} p<0.05$, one-way ANOVA comparing mean values of freezing of the three groups each day, followed by Newman-Keuls post hoc test; in case of cued memory, two-way ANOVA followed by Bonferroni's post hoc test was performed.

duces changes in freezing response even when animals are not reexposed to the training context, we performed two other experiments comparing the freezing levels of non-reexposed animals injected with Decoy (NoR-Decoy) and non-reexposed animals injected with mDecoy (NoR-mDecoy). In the first experiment, mice were trained, $24 \mathrm{~h}$ later were injected, and tested $1 \mathrm{~d}$ after injection. No significant differences were found between groups (mean \pm SEM of freezing response for NoR-mDecoy: $36.30 \pm$ 6.73, $n=9$; for NoR-Decoy: $37.12 \pm 1.92, n=11 ; t$ test: $t=0.13$, $p=0.90)$. In the second experiment, mice were trained, $24 \mathrm{~h}$ later were injected, and tested $4 \mathrm{~h}$ later. No significant differences were found between groups (mean \pm SEM of freezing response for NoR-mDecoy: $39.17 \pm 3.23, n=8$; for NoR-Decoy: $44.66 \pm$ 9.53, $n=8 ; t$ test: $t=0.53, p=0.65)$. Together, the last two experiments indicate that Decoy treatment had effect only when memory was reactivated after context reexposure and that memory reactivation session itself does not impact on freezing levels.

The results of this section indicate that NF- $\kappa \mathrm{B}$ inhibition in the hippocampus impairs contextual fear reconsolidation and that the impairment is persistent, considering that no spontaneous recovery of memory impairment occurs for at least $14 \mathrm{~d}$. In a previous report, the amnesic effect of another direct inhibitor of NF- $\kappa \mathrm{B}$, SN50, was determined in rat fear conditioning reconsolidation. At variance with the present report, the authors used intracerebroventricular administration, and thus, the effect of NF- $\kappa$ B inhibition locally in the hippocampus was not evaluated. The persistence of the impairment effect 1 or 2 weeks after reconsolidation was also not evaluated (Lubin and Sweatt, 2007).

\section{$\mathrm{NF}-\kappa \mathrm{B}$ is activated by reconsolidation induction}

The former experiment suggests that $\mathrm{NF}-\kappa \mathrm{B}$ is required in the hippocampus for reconsolidation of contextual fear conditioning. To gain additional insight, we performed a time course analysis of $\mathrm{NF}-\kappa \mathrm{B}$ activity in hippocampus during reconsolidation. Immediately after a 5 min reexposure, the mice were killed by cervical dislocation (0 time point) or individually placed in their home cages for 15 or $45 \mathrm{~min}$ before being killed (Fig. $2 a$, S-R). In addition, a group of animals not shocked during training and killed 15 min after context reexposure (US-R) and a group of animals trained but not reexposed and killed $24 \mathrm{~h}$ after training (S-NoR) were added. The hippocampus was dissected and nuclear extracts were obtained. We performed a gel shift assay using an NF- $\kappa$ B probe. This method estimates nuclear translocation of NF- $\kappa \mathrm{B}$ and specific DNA binding activity. We obtained three specific retarded bands with this probe (Fig. $2 b$ ), as previously described (Freudenthal et al., 2005). The higher band, corresponding to the p65/p50 heterodimer, was quantified and compared with basal activity of a nonstimulated group of animals (naive group) that were run simultaneously. In the trained and reexposed groups $(\mathrm{S}-\mathrm{R})$, we found a significant inhibition of NF- $\kappa \mathrm{B}$ at 0 time point ( $t$ test: $t=2.47, p<0.05$ ) and a significant increase of NF- $\kappa \mathrm{B}$ activity $15 \mathrm{~min}$ after training ( $t$ test: $t=4.8, p<0.001)$, which returned to basal levels after 45 min (Fig. $2 c, d$ ). Conversely, US-R and S-NoR groups showed similar levels of activity to the naive group (Fig. $2 c, d$ ).

These results, together with those of the first experiment, support that, after an initial inhibition, NF- $\kappa \mathrm{B}$ is specifically activated in the hippocampus by memory reactivation and that such activation is required for memory reconsolidation.

\section{NF- $\kappa$ B inhibition in the hippocampus enhances fear memory extinction}

In the first experiment, we found that NF- $\kappa \mathrm{B}$ inhibition, after a brief reexposure to the training context, impairs memory. In the following experiment, we tested the effect of NF- $\kappa$ B inhibition on memory shortly after prolonged reexposure. As in the previous 
experiment, three groups of mice were trained for cue and contextual fear conditioning, injected with Decoy or $\mathrm{mDecoy}$ $24 \mathrm{~h}$ later, and either reexposed for $30 \mathrm{~min}$ (extinction session) (E-Decoy and E-mDecoy groups) or not reexposed (NoEDecoy group) (Fig. 3a). A high level of freezing was initially found in the extinction session (day 2) and a similar decrease in freezing behavior for both extinguished groups was observed during the $30 \mathrm{~min}$ of reexposure [first $5 \mathrm{~min}$ : E-Decoy (39.54 \pm $3.93)$ vs E-mDecoy (41.82 \pm 4.07$)$; last 5 min: E-Decoy $(8.94 \pm 1.94)$ vs E-mDecoy (11.06 \pm 2.57$)$; repeated-measures twoway ANOVA: main effect of time: $F_{(1,20)}$ $=188.9, p<0.0001$; main effect of group: $F_{(2,20)}=0.2979, p=0.5912$; interaction: $F_{(2,20)}=0.001, p=0.9730$; Bonferroni's post hoc test between first 5 min reexposure and last $5 \mathrm{~min}$ reexposure: E-mDecoy, $p<0.001$; E-Decoy, $p<$ 0.001]. After the extinction session on the following day (day 3), all groups were tested for contextual conditioning, and on day 4 they were tested for cued conditioning. One and 2 weeks after the extinction session, mice were retested for contextual conditioning. As shown in Figure $3 b$, reexposed groups (E-Decoy and mDecoy) showed a significantly lower level of freezing than the non-reexposed group (NoEDecoy) as a consequence of extinction induction (ANOVA: $F_{(2,28)}=21.67, p<$ 0.0001; Newman-Keuls post hoc test: NoE-Decoy vs E-mDecoy, $p<0.001$, and NoE-Decoy vs E-Decoy, $p<0.001$ ). This result suggests that NF- $\kappa \mathrm{B}$ inhibition does not impair extinction, and thus, in contrast to the previous experiment with $5 \mathrm{~min}$ reexposure, $\mathrm{mDecoy}$ - and Decoy-injected groups showed similar values of freezing. The cued conditioning test on day 4 showed high levels of freezing for the three groups, indicating that cued conditioning was not affected by contextual extinction treatment and by Decoy administration in the hippocampus (repeatedmeasures two-way ANOVA: main effect of time: $F_{(1,28)}=147.9$, $p<0.0001$; main effect of group: $F_{(2,28)}=0.7891, p=0.4641$; interaction: $F_{(2,28)}=0.2198, p=0.8041$; Bonferroni's post hoc test between pretone and tone: NoE-Decoy, $p<0.001$; E-mDecoy, $p<0.001$; E-Decoy, $p<0.001)$. As expected, in the second contextual test 1 week after the extinction session, the group of animals that were injected with mDecoy and received the treatment for extinction (E-mDecoy) showed a similar high level of freezing compared with the nonextinguished group (NoE-Decoy), indicating a spontaneous recovery of the conditioned response. Remarkably, the group of animals that were injected with Decoy and that received the treatment for extinction (E-Decoy) showed significantly lower levels of freezing than the other two groups (ANOVA: $F_{(2,28)}=5.873, p<0.001$; Newman-Keuls post hoc test: NoE-Decoy vs E-Decoy, $p<0.01$, and E-mDecoy vs E-Decoy, $p<0.05)$.

Two explanations for the differences between E-mDecoy and E-Decoy groups can be offered as follows: (1) the original memStudent's $t$ test.

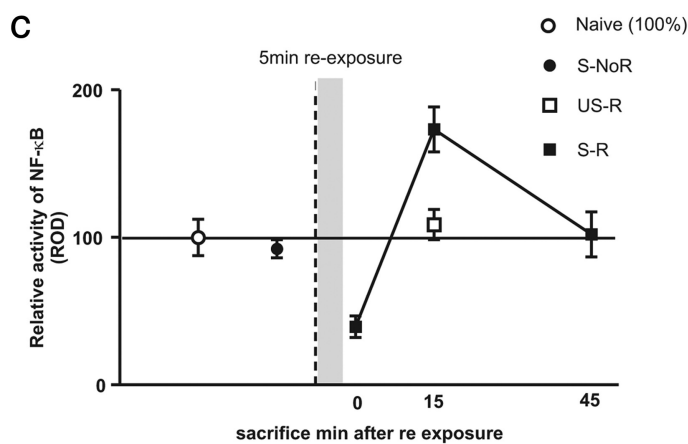

d

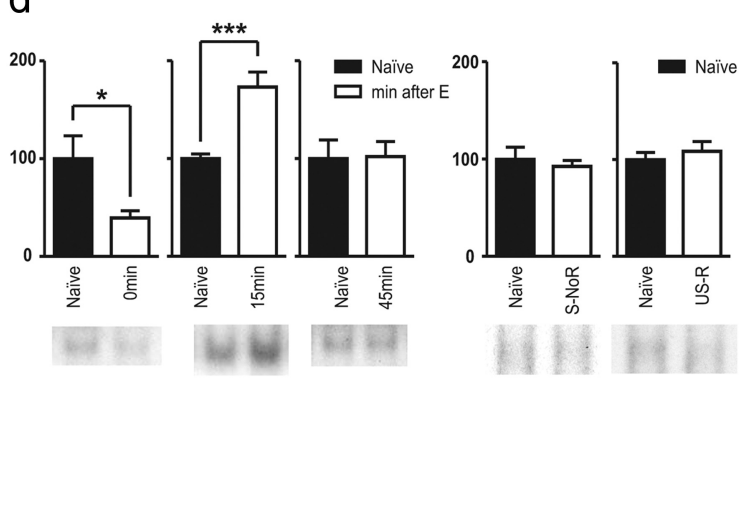

Figure 2. Temporal course of NF- $\kappa B$ activity after 5 min reconsolidation session, estimated by EMSA. Data are expressed as 列

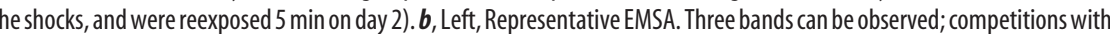
the schematic graph seen in $c$ was performed. Representative p65/p50 EMSA bands are shown. ${ }^{*} p<0.05$; ${ }^{* * *} p<0.001$;

ory was impaired because of labilization after retrieval, and (2) extinction was enhanced and spontaneous recovery was delayed or impaired. The third testing, 2 weeks after the extinction session, clarified the interpretation of the results. In this test, all groups showed similar high levels of freezing, indicating that the conditioned response of the E-Decoy group underwent spontaneous recovery, and confirming that the original memory was not affected by Decoy treatment.

The overall conclusion of the present experiment is that $\mathrm{NF}-\kappa \mathrm{B}$ inhibition during and/or shortly after prolonged presentation of the conditioned stimulus (CS) produces an extinction enhancement that causes delay of spontaneous recovery, although as time passes, the conditioned response is recovered.

\section{NF- $\kappa \mathrm{B}$ is not activated by extinction induction}

Next, we determined whether prolonged reexposure that induces extinction causes a different NF- $\kappa$ B activity profile than that observed after reconsolidation. A group of animals were trained and $24 \mathrm{~h}$ later were reexposed for $30 \mathrm{~min}$ to the training context (S-E). We assessed freezing during this session and observed a similar decrease in the response for both extinguished groups (data not shown). At 0,15 , or $45 \mathrm{~min}$ after reexposure, the animals were killed and hippocampal nuclear extracts were obtained (Fig. 4a). 
a

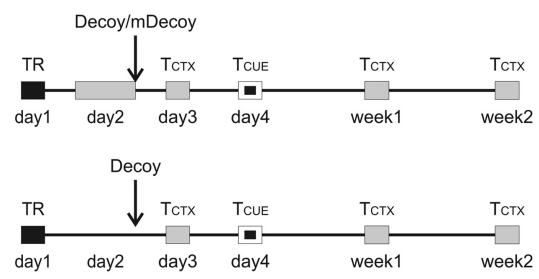

b

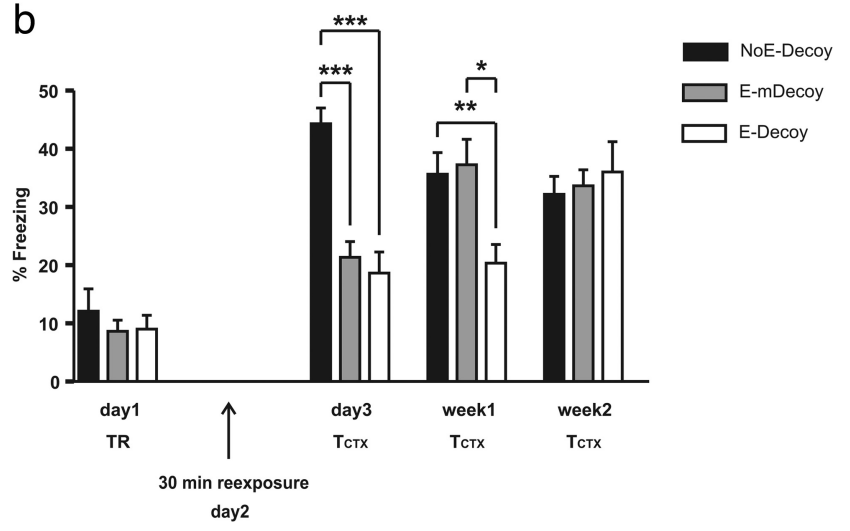

Figure 3. NF- $\kappa$ B inhibition in the hippocampus enhances contextual fear memory extinction. Data are expressed as mean \pm SEM of freezing response. $\boldsymbol{a}$, Design of the experiment. All groups were trained at day 1 ; at day 2 , animals were either reexposed for $30 \mathrm{~min}$ to the training context and injected with m-Decoy (E-mDecoy) $(n=11)$ or with Decoy (E-Decoy) $(n=9)$, or were non-reexposed and injected with Decoy (NoE-Decoy) $(n=8)$. TR, Training session; Tctx, contextual test; Tcue, cued test. $\boldsymbol{b}$, Effect of NF- $\kappa$ B inhibition in contextual memory extinction. ${ }^{*} p<0.05$; ${ }^{* *} p<0.01 ;{ }^{* * *} p<0.001$; one-way ANOVA comparing mean values of freezing of the three groups each day, followed by NewmanKeuls post hoc test.
A naive group was formed simultaneously to determine basal activity. As shown in Figure $4, b$ and $c$, no significant changes in NF- $\kappa \mathrm{B}$ activity were found, although a tendency for inhibition can be observed at 15 and $45 \mathrm{~min}$ after reexposure ( $t$ test: naive vs $0 \mathrm{~min}, t=0.23 ; p=0.82 ; t$ test: naive vs $15 \mathrm{~min}, t=1.35 ; p=0.20$; $t$ test: naive vs $45 \mathrm{~min}, t=1.18 ; p=0.26)$. NF- $\kappa$ B activity was also measured immediately after a $20 \mathrm{~min}$ reexposure $(-10 \mathrm{~min}$ time point) ( $t$ test: naive vs $0 \mathrm{~min}, t=0.77 ; p=0.45$ ). Considering the beginning of the reexposure, the -10 time point coincides with the time point in which a peak of NF- $\kappa \mathrm{B}$ activity was found in reconsolidation (Fig. 2b). In contrast to reconsolidation, no significant increase in NF- $\kappa \mathrm{B}$ activity was observed in the present experiment (Fig. $4 b, c$ ).

On the basis of these last findings, we hypothesized that NF- $\kappa \mathrm{B}$ activation is blocked when context reexposure is prolonged. We further postulate that $\mathrm{CaN}$ phosphatase induces such an inhibition by means of direct dephosphorylation of NF- $\kappa \mathrm{B}$ or dephosphorylation of its inhibitor, I $\kappa$ B. Thus, the following experiments were performed to test this hypothesis.

\section{CaN inhibition in the hippocampus impairs extinction but not reconsolidation}

Previous reports support that the phosphatase $\mathrm{CaN}$ is involved in extinction (Lin et al., 2003a; Baumgärtel et al., 2008; Havekes et al., 2008). However, these studies were performed either in amygdala or in the whole forebrain. In the following experiment, we analyzed the effect of CaN inhibition in the hippocampus by local administration of FK, a specific CaN inhibitor. Three groups of mice were trained for fear conditioning, injected $24 \mathrm{~h}$ later in the hippocampus with FK or vehicle (DMSO), and either reexposed for 30 min (extinction session) (E-FK and E-DMSO groups) or not reexposed (NoE-FK group). High levels of freezing were initially found. A similar decrease in freezing behavior was observed during the $30 \mathrm{~min}$ of reexposure for extinguished groups [first $5 \mathrm{~min}$ : E-FK $(61.48 \pm 6.7)$ vs E-DMSO (52.41 \pm 8.24); last 5 min: E-Decoy $(12.5 \pm 4.84)$ vs E-mDecoy (19.67 \pm 5.51$)$; repeated-measures two-way ANOVA: main effect of time: $F_{(1,16)}=29.76, p<0.001$; main effect of group: $F_{(1,16)}=0.9642, p=0.002$; interaction: $F_{(1,16)}=1.017, p=0.3350$; Bonferroni's post hoc test between first 5 min reexposure and last $5 \mathrm{~min}$ reexposure: $\mathrm{E}$ DMSO, $p<0.05$; E-FK, $p<0.001]$. One day after the extinction session (day 3 ), all groups were tested for contextual conditioning (Fig. 5a). As shown in Figure 5b, the reexposed group injected with vehicle (EDMSO) showed significantly lower levels of freezing than the non-reexposed group (NoE-FK), as a consequence of extinction (ANOVA: $F_{(2,24)}=8.775, p<0.01$; Newman-Keuls post hoc test: NoE-FK vs EDMSO, $p<0.01$, and E-DMSO vs E-FK, $p<0.01)$. However, the reexposed group injected with $\mathrm{CaN}$ inhibitor showed higher levels of freezing. Cued fear conditioning test showed normal freezing to tone (repeated-measures two-way ANOVA: main effect of time, $F_{(1,24)}=46.00, p<0.0001$; main effect of group, $F_{(2,24)}=0.1480, p=$ 0.8632 ; interaction, $F_{(2,24)}=0.4082, p=$
Figure 4. Temporal course of NF- $\kappa$ B activity in extinction, estimated by EMSA. Data are expressed as mean ROD values \pm SEM $\boldsymbol{a}$, Design of the experiment. Animals were killed immediately ( 0 min time point), 15 or 45 min after 30 min extinction session (S-E). A point of -10 min was also performed, in which animals were killed immediately after 20 min extinction session. Naive group was used for basal activity estimation. $\boldsymbol{b}$, Schematic graph with NF- $\kappa$ B activity from all groups together is shown. $n=9-10$ in each group. NF- $\kappa$ B activity was estimated by densitometric analysis (ROD) of the $p 65 / p 50$ band, obtained with hippocampal nuclear extracts from animals of the different groups by gel shift. $c$, Graphs comparing NF- $\kappa$ B activity from each S-E group with their respective naive are shown. With these values, the schematic graph seen in $\boldsymbol{b}$ was performed. Representative p65/p50 EMSA bands are shown; Student's $t$ test. 
0.6694; Bonferroni's post hoc test between pretone and tone: NoE-FK, $p<$ 0.001 ; E-DMSO, $p<0.01$; E-FK, $p<$ $0.01)$. Similar high levels of freezing were observed for all groups 1 week after injection because the E-DMSO group underwent spontaneous recovery. These results indicate that the inhibition of $\mathrm{CaN}$ in the hippocampus impaired fear conditioning extinction.

For the following experiment, we used the same design as in the previous experiment, but on day 2 the mice were reexposed for $5 \mathrm{~min}$ instead of $30 \mathrm{~min}$ (Fig. $5 c$ ). All groups showed high levels of freezing at testing, indicating that CaN inhibition had no effect on memory reconsolidation (Fig. $5 d$ ).

To test whether FK administration produces changes in freezing response even when animals are not reexposed to the training context, we performed another experiment comparing the freezing levels of non-reexposed animals injected with FK (NoR-FK) and non-reexposed animals injected with DMSO (NoRDMSO). Mice were trained and $24 \mathrm{~h}$ later were injected and tested $1 \mathrm{~d}$ after injection. No significant differences were found between groups (mean \pm SEM of freezing response for NoR-DMSO, $32.92 \pm 3.60$; for NoR-FK, $42.38 \pm 7.67 ; t$ test: $t=2.04, p=0.06)$. The last experiment indicates that FK treatment had only effect when memory was reactivated after context reexposure.

\section{CaN inhibition during extinction enhances NF- $\kappa$ B activity}

The previous experiments suggested that $\mathrm{CaN}$ is involved in the hippocampus for extinction formation but not for reconsolidation. Conversely, NF- $\kappa \mathrm{B}$ is necessary for reconsolidation but not for extinction, and, in fact, NF- $\kappa \mathrm{B}$ is activated in reconsolidation but not in extinction. We evaluated whether $\mathrm{CaN}$ inhibition during extinction formation allows for hippocampal NF- $\kappa \mathrm{B}$ activation. Two groups of mice were used (E-FK and E-DMSO), and animals were killed 15 min after the reexposure session of $30 \mathrm{~min}$ (Fig. 5e, top diagram). A gel shift assay was performed, showing significantly higher levels of $\mathrm{NF}-\kappa \mathrm{B}$ activity for the group injected with $\mathrm{CaN}$ inhibitor (E-FK) than the group injected with vehicle (E-DMSO) ( $t$ test: $t=3.36$, $p<0.01$ ) (Fig. 5e). A comparison between non-reexposed groups NoE-DMSO and NoE-FK was included to control an effect of FK on NF- $\kappa \mathrm{B}$ activity even when animals were not reexposed. No significant differences were found between these groups, indicating that when extinction is not induced, FK does not enhance $\mathrm{NF}-\kappa \mathrm{B}$ activity [mean \pm SEM relative activity of NF- $\kappa \mathrm{B}$ (ROD) for NoR-DMSO: $100.0 \pm 3.13, n=10$; for NoR-FK: $100.2 \pm 1.9$, $n=10$; $t$ test: $t=0.051, p=0.96]$. These results suggest that $\mathrm{CaN}$ prevents NF- $\kappa \mathrm{B}$ activation as part of the mechanisms Student's $t$ test.
C

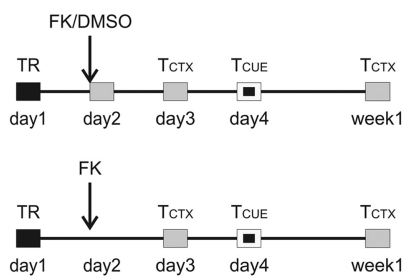

d

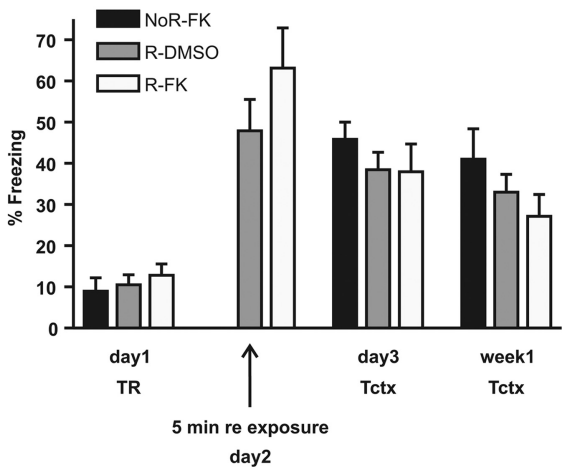

e
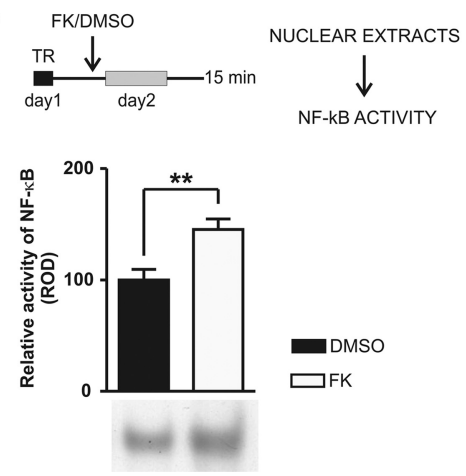

Figure 5. CaN inhibition in the hippocampus impairs extinction but not reconsolidation. $\boldsymbol{a}-\boldsymbol{d}$, Data are expressed as mean \pm SEM of freezing response. $\boldsymbol{a}$, Design of the extinction experiment shown in $\boldsymbol{b}$. All groups were trained at day $1 ;$ at 2, animals were either reexposed for 30 min to the training context and injected with DMSO (E-DMSO) $(n=8)$ or with FK (E-FK) $(n=8)$, or were non-reexposed and injected with FK (NoE-FK) $(n=8)$. TR, Training session; Tctx, contextual test; Tcue, cued test. $\boldsymbol{b}$, Effect of CaN inhibition in contextual memory extinction. c, Design of the reconsolidation experiment $\boldsymbol{d}$. Groups are as in $\boldsymbol{a}$, but for a 5 min reexposure: non-reexposed animals injected with FK (NoR-FK) $(n=8)$ reexposed injected with vehicle (R-DMSO) $(n=12)$, and reexposed injected with FK (R-FK) $(n=10)$. $\boldsymbol{d}$, Effect of CaN bition in contextual memory reconsolidation. $\boldsymbol{a}-\boldsymbol{d}{ }^{* *} p<0.01$; one-way ANOVA comparing mean values of freezing 0 ups each day, followed by Newman-Keuls post hoc test. $\boldsymbol{e}$, Effect of CaN inhibition on NF- $\kappa$ B activity. Left, 0 n 2, trained animals were injected either with FK or with DMSO and reexposed for 30 min to the TR context. Fifteen after extinction session, animals were killed and NF- $\kappa$ B activity was estimated by densitometric analysis (ROD) o the $p 65 / p 50$ band (EMSA). The graph shows mean ROD values \pm SEM. Representative bands are shown. ${ }^{* *} p<0.01$,

involved in extinction, and thus the inhibition of CaN during extinction session releases NF- $\kappa \mathrm{B}$ from that restraint.

$\mathrm{CaN}$ may act on NF- $\kappa \mathrm{B}$ directly by dephosphorylation of $\mathrm{p} 65$, a component of the NF- $\kappa \mathrm{B}$ dimer that is phosphorylated in the process of activation by protein kinase $\mathrm{A}$, or indirectly by dephosphorylation of a protein upstream in the NF- $\kappa \mathrm{B}$ activation pathway, like the NF- $\kappa \mathrm{B}$ inhibitor, $\mathrm{I} \kappa \mathrm{B}$ (Pons and Torres-Aleman, 2000; Biswas et al., 2003). Experiments are ongoing to determine the mechanism of $\mathrm{CaN}$ inhibition on the NF- $\kappa \mathrm{B}$ pathway.

\section{NFAT inhibition impairs extinction}

NFAT is a transcription factor evolutionarily related to the Rel/ NF- $\kappa \mathrm{B}$ family (Chytil and Verdine, 1996) that is activated by $\mathrm{Ca}^{2+}$ signals by means of $\mathrm{CaN}$ activation and dephosphorylation. Dephosphorylation unmasks several nuclear localization signals 
a
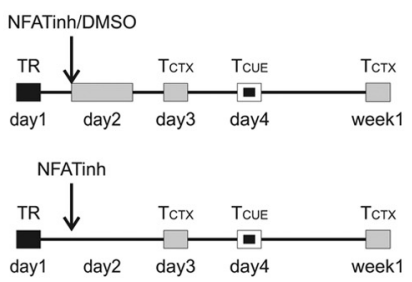

b

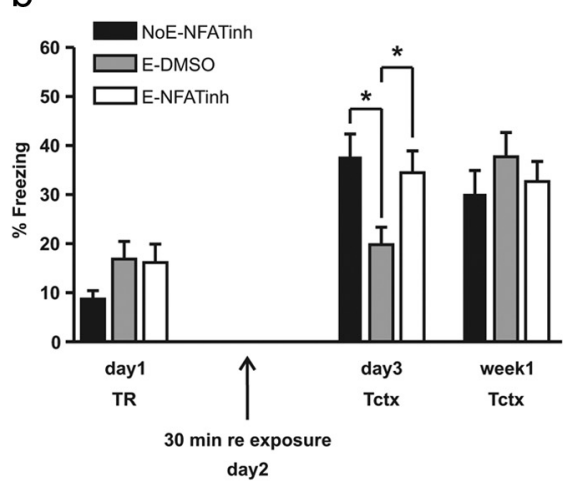

C
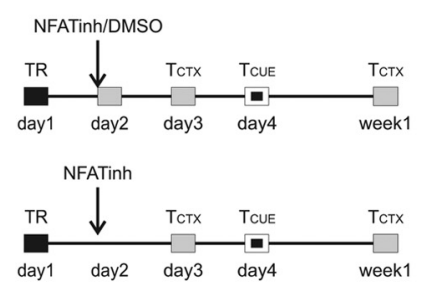

d

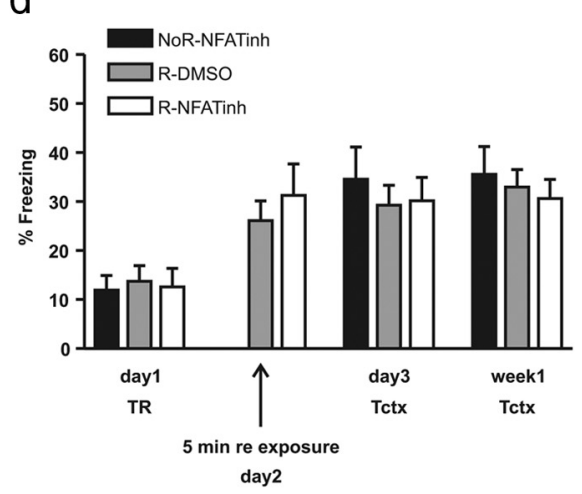

Figure 6. NFAT inhibition in the hippocampus impairs extinction but not reconsolidation. $\boldsymbol{a}-\boldsymbol{d}$, Data are expressed as mean \pm SEM of freezing response. $\boldsymbol{a}$, Design of the extinction experiment shown in $\boldsymbol{b}$. All groups were trained at day 1 ; at day 2, animals were either reexposed for 30 min to the training context and injected with DMSO (E-DMSO) $(n=8)$ or with NFAT inhibitor (E-NFATinh) $(n=8)$, or were non-reexposed and injected with NFAT inhibitor (NoE-NFATinh) $(n=9)$. TR, Training session; Tctx, contextual test; Tcue, cued test. $\boldsymbol{b}$, Effect of NFAT inhibition in contextual memory extinction. $\boldsymbol{c}$, Design of the reconsolidation experiment shown in $\boldsymbol{d}$. Groups are as in $\boldsymbol{a}$, but for a 5 min reexposure: non-reexposed animals injected with NFAT inhibitor (NoR-NFATinh) $(n=8)$, reexposed injected with vehicle (R-DMSO) $(n=9)$ and reexposed injected with NFAT inhibitor (RNFATinh) $(n=9)$. $\boldsymbol{d}$, Effect of NFAT inhibition in contextual memory reconsolidation. ${ }^{* *} p<0.05$; one-way ANOVA comparing mean values of freezing of the three groups each day, followed by Newman-Keuls post hoc test.

and allows for NFAT translocation into the nucleus (Sugiura et al., 2001). The experiments of the previous section suggest that $\mathrm{CaN}$ is involved in extinction, preventing NF- $\kappa \mathrm{B}$ activation induced by retrieval. In the following experiment, we explored NFAT as a target for $\mathrm{CaN}$ regulation of gene expression in extinction. First, we evaluated the effect of a cell-permeable peptide (11R-VIVIT), a specific NFAT inhibitor that blocks the NFAT docking site for CaN (Noguchi et al., 2004), on extinction. Three groups of mice that were trained for fear conditioning were injected in the hippocampus with the NFAT inhibitor or with vehicle (DMSO) $24 \mathrm{~h}$ later and either reexposed for $30 \mathrm{~min}$ (extinction session) (E-NFATinh and E-DMSO groups) or not reexposed (NoE-NFATinh group). High levels of freezing followed by a decrease in freezing behavior were observed for both extinguished groups during the $30 \mathrm{~min}$ of reexposure [first $5 \mathrm{~min}$ : E-NFATinh $(29.67 \pm 4.05)$ vs E-DMSO (31.82 \pm 5.18$)$; last 5 min: E-NFATinh $(14.17 \pm 3.52)$ vs E-DMSO (18.79 \pm 3.45$)$; repeated-measures two-way ANOVA: main effect of time: $F_{(1,16)}=$ 20.00, $p<0.001$; main effect of group: $F_{(1,16)}=0.4738, p=$ 0.4996; interaction: $F_{(1,16)}=0.1497, p=0.7031$; Bonferroni's post hoc test between first $5 \mathrm{~min}$ reexposure and last $5 \mathrm{~min}$ reexposure: E-DMSO, $p<0.05$; E-NFATinh, $p<0.05$ ]. On day 3 , all groups were tested for contextual conditioning (Fig. $6 a$ ). The reexposed group injected with vehicle (E-DMSO) showed significantly lower levels of freezing than the non-reexposed group (NoE-NFATinh) as a consequence of extinction (ANOVA: $F_{(2,25)}$ $=4.953 ; p<0.05$; Newman-Keuls post hoc test: NoE-NFATinh vs E-DMSO, $p<0.05$ ) (Fig. $6 b$ ). However, the reexposed group injected with the NFAT inhibitor showed higher levels of freezing (Newman-Keuls post hoc test: E-DMSO vs E-NFATinh, $p<$ $0.05)$. On day 4 , cued fear conditioning test showed normal freez- ing to tone (repeated-measures two-way ANOVA: main effect of time: $F_{(1,25)}=$ 41.37, $p<0.0001$; main effect of group: $F_{(2,25)}=0.3348, p=0.7189$; interaction: $F_{(2,25)}=0.0963, p=0.9086$; Bonferroni's post hoc test between pretone and tone: NoE-NFATinh, $p<0.05$; E-DMSO, $p<$ 0.01 ; E-NFATinh, $p<0.01$ ). Similar levels of freezing were observed for all groups 1 week after injection. These results indicate that NFAT inhibition in hippocampus impairs fear conditioning extinction.

In the following experiment, we used the same design described above, but on day 2 , the mice were reexposed for $5 \mathrm{~min}$ instead of $30 \mathrm{~min}$ (Fig. $6 c$ ). All groups showed high levels of freezing at testing, indicating that NFAT inhibition had no effect on memory reconsolidation (Fig. $6 d)$.

To test whether NFAT inhibitor administration produces changes in freezing response even when animals are not reexposed to the training context, we performed another experiment comparing the freezing levels of non-reexposed animals injected with NFAT inhibitor (NoRNFATinh) and non-reexposed animals injected with DMSO (NoR-DMSO). Mice were trained, $24 \mathrm{~h}$ later were injected, and tested $1 \mathrm{~d}$ after injection. No significant differences were found between groups (mean \pm SEM of freezing response for NoR-DMSO: $26.52 \pm$ 4.19; for NoR-NFATinh: $34.59 \pm 6.55$; $t$ test: $t=1.09, p=0.29$ ). The last experiment indicates that NFATinh treatment had effect only when memory was reactivated after context reexposure.

\section{Both CaN and NFATc4 translocate into the nucleus $45 \mathrm{~min}$ after extinction induction}

In previous experiments, we found that memory extinction was impaired by means of CaN and NFAT inhibition in hippocampus. These results indicate that both proteins are involved in the formation of the extinction memory. Thus, we hypothesized that $\mathrm{CaN}$ and NFAT translocate into the nucleus to regulate gene expression (Sugiura et al., 2001). We performed the following experiment to test whether a translocation occurs after extinction induction. One day after training, mice were reexposed to the training context for $30 \mathrm{~min}$, and 0,15 , or $45 \mathrm{~min}$ later they were killed (Fig. $7 a, \mathrm{~S}-\mathrm{E}$ ). We also performed a group of animals killed immediately after $20 \mathrm{~min}$ of reexposure $(-10$ time point). The hippocampus was dissected and nuclear and cytosolic extracts were obtained. Western blots were performed with $\mathrm{CaN}$ and NFATc4 antibodies. We studied NFATc4 because it is an important isoform present in hippocampal neurons related to neural plasticity (Groth and Mermelstein, 2003). The band obtained with each antibody was quantified relative to the value of a housekeeping protein (actin for cytosolic extracts and lamin B for nuclear extracts). Ratios between nuclear and cytosolic signals (translocation index) were determined at different times and were compared with the basal activity of a nonstimulated group of animals (naive group) performed simultaneously. A significant increment in $\mathrm{CaN}$ and NFATc4 translocation was found 45 min after extinction induction $(\mathrm{CaN}$ : $t$ test, $t=2.283, p<0.05$; 
NFATc4: $t$ test, $t=2.158, p<0.05$ ) (Fig. $7 b, c)$. No differences were observed between controls (US-E and S-NoE) and naive (Fig. 7d). Accordingly, the CaN inhibitor FK impaired CaN and NFATc4 nuclear translocation 45 min after extinction session (CaN: $t$ test: $t=3.243, p<$ 0.01; NFATc4: $t$ test: $t=3.358, p<0.01$ ) (Fig. 7e), suggesting that CaN translocates into the nucleus and, at the same time, promotes the translocation of NFATc4.

\section{Discussion}

In associative learning, retrieval and memory reactivation by conditioned stimulus presentation can induce two apparently opposing processes, reconsolidation and extinction. In the present report, we describe two transcriptional mechanisms that are differentially induced in either reconsolidation or extinction. To our knowledge, these findings provide the first insight into the molecular mechanisms that determine the direction of memory reprocessing after retrieval. We found that NF- $\kappa \mathrm{B}$ is activated in the hippocampus and that such activation is necessary for memory reconsolidation. The hippocampal inhibition of NF- $\kappa \mathrm{B}$ in reconsolidation caused retention deficit for at least 2 weeks, suggesting permanent memory impairment. In contrast, we found that hippocampal CaN activity is necessary for extinction. CaN plays a dual role; it blocks NF- $\kappa \mathrm{B}$ activation and it induces NFAT activation and translocation. In fact, CaN inhibition in the hippocampus impaired extinction, blocking both its own translocation and that of NFATc4, and allowing for NF- $\kappa \mathrm{B}$ activation. Our observations suggest that, under $\mathrm{CaN}$ inhibition, reconsolidation was induced despite prolonged reexposure, a treatment that normally induces extinction.

Alternative interpretations of the present results can be offered. Some authors suggested that reconsolidation impairments are not permanent and retrieval disruption recovers over time (Lattal and Abel, 2004). Although we cannot rule out such interpretation, in the reconsolidation experiment

(Fig. 1) we found memory impairment at such long-term periods as 2 weeks, suggesting that memory interference is not short-lasting. In addition, the authors suggested that impairment effects found with pharmacological manipulations in reconsolidation are attributable to extinction enhancement that produces a delay in spontaneous recovery. Another alternative interpretation is that extinction is not a boundary condition on reconsolidation (Duvarci et al., 2006), and thus, in the experiment of extinction, Decoy treatment could potentially interfere not only with extinction consolidation but also with the original memory reconsolidation. Nevertheless, the results obtained in the extinction experiment (Fig. 3) make those interpretations hardly tenable. In fact, we observed spontaneous re-
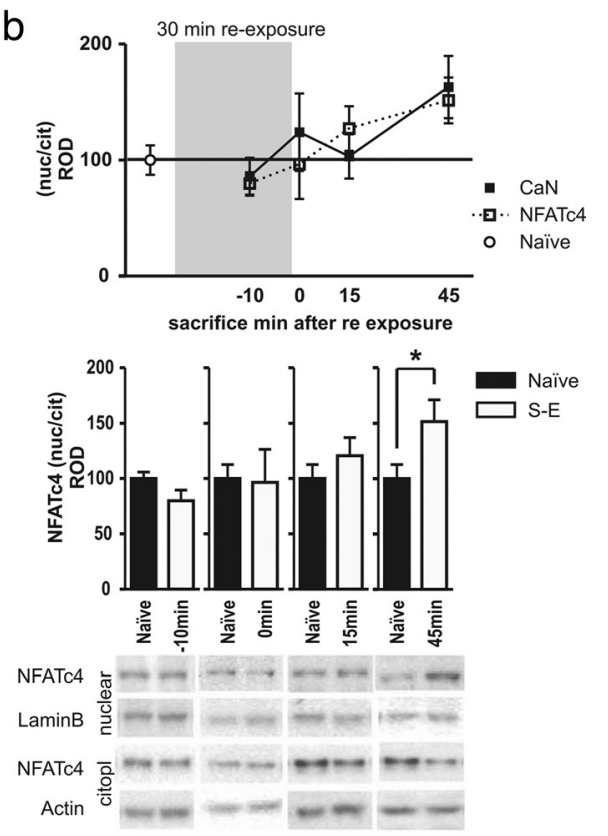

e

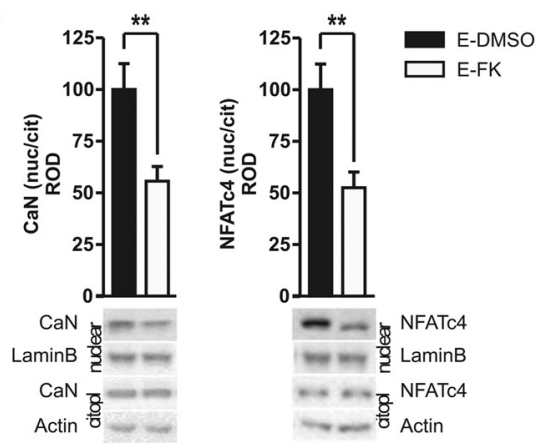

Figure 7. CaN and NFATc4 nuclear translocation after extinction induction. Data are expressed as mean \pm SEM nuclear translocation index. $\boldsymbol{a}$, Design of the experiment. Animals were killed immediately ( 0 min time point), 15 or 45 min after 30 min extinction session (S-E). A point of -10 min was also performed, in which animals were killed immediately after 20 min extinction

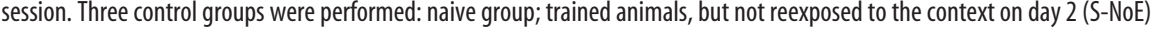
Animals were placed in the training chamber on day 1, received the tones but not the shocks, and were reexposed 30 min on day animals (S-E) compared with naive. Nuclear translocation indexes were estimated by densitometric analysis (ROD) of CaN and NFATc4 specific bands obtained by Western blots. Each time point was compared with its respective naive. c, Left, CaN mean \pm 作 in each group. Below graphs, The respective representative bands obtained by Western blots. Right, The same as in left but for NFATc4. $\boldsymbol{d}$, Graphs showing no differences between control groups (S-NoE and US-E) on CaN or NFATc4 nuclear translocation. Below and NFATc4 nuclear translocation. Left, 0n day 2, trained animals were injected with FK or with DMS0, and reexposed for 30 min The TR context. Forty-five minutes after extinction session, animals were killed, and CaN and NFAT nuclear translocation was assessed by Western blot. Right, The same as in left but for NFATc4. Below graphs, The respective representative bands obtained with Western blot. ${ }^{*} p<0.05$; ${ }^{* *} p<0.01$; Student's $t$ test.

covery of the freezing response 1 week after training for control extinguished group (E-mDecoy) and 2 weeks after training for extinguished animals treated with Decoy (E-Decoy). Thus, the lack of freezing recovery on Decoy-treated animals (R-Decoy) in the reconsolidation experiment indeed supports a real impairment of the original memory, whereas the delay in spontaneous recovery provoked by the same treatment in the extinction experiment supports extinction enhancement. The finding of a delay in spontaneous recovery would be of importance for the potential development of fear-related disorders treatments. In relation to this, other studies has also found extinction enhancement using the drug D-cycloserine (DCS). In a first study, Ledgerwood et al. (2004) found that the 


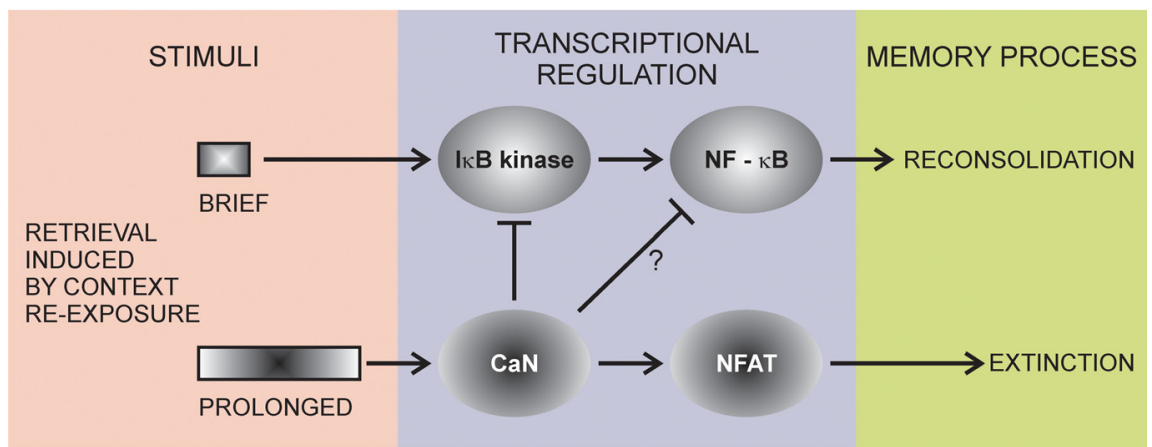

Figure 8. Transcription factor switch between reconsolidation and extinction. Under a brief reexposure to the training context, transcription factor NF- $\kappa \mathrm{B}$ is activated and induces its target genes expression. This brief stimulus leads to reconsolidation. In contrast, if the stimulus is prolonged, phosphatase CaN gets activated and blocks NF- $\kappa$ B activation. CaN also activates NFAT transcription factor by direct dephosphorylation. This, in turn, would activate its target genes expression. CaN and NFAT translocate to the nucleus as a complex, thus impeding the NFAT rephosphorylation. In this case, extinction of memory takes place.

original memory in drug-administered animals could not be reinstated. However, in a second paper, although the extinction was more pronounced in animals injected with DCS than in controls, the spontaneous recovery was similar in both groups (Ledgerwood et al., 2005). Thus, the extinction enhancement induced by DCS seems to have different characteristics to those found in the present study using the NF- $\kappa \mathrm{B}$ inhibitor.

The inhibition of both CaN and NFAT in the hippocampus impaired extinction but did not affect reconsolidation, indicating that these proteins are part of the molecular mechanisms of extinction that play no role in reconsolidation. In contrast, NF- $\kappa \mathrm{B}$ inhibition impairs memory reconsolidation and, remarkably, enhances memory extinction. Our finding suggests that a restriction of this transcription factor is part of the mechanism involved in extinction, and thus the inhibition of NF- $\kappa \mathrm{B}$ by Decoy reinforces the process that normally occurs in the hippocampus, strengthening the action of $\mathrm{CaN}$ toward negative modulation of neural plasticity on the original memory trace.

To our knowledge, our study is the first to show a role of NFAT in memory processes. The role of NFAT in the nervous system has been studied only recently, particularly, the discovery of NFATc4 (also named NFAT3) in the hippocampus (Graef et al., 1999). The canonical way of NFAT activation by CaN is well known in other systems (Sugiura et al., 2001), and our report also supports this mechanism of activation. Considering such canonical pathway, the signaling cascade is likely that NFAT activation is dependent of CaN action. Our finding that FK not only inhibited CaN translocation but also inhibited NFAT translocation, supports this canonical pathway and not an action of NFAT on CaN. In fact, the NFAT inhibitor used in the present study acts by interfering specifically with the activation site of CaN.

One key downstream target for NFAT in the nucleus is the BDNF promoter (Groth et al., 2007; Vashishta et al., 2009). In addition, it has been shown that NFAT is able to bind NF- $\kappa \mathrm{B}$ consensus sequences (Casolaro et al., 1995). In such case, a competition between these two transcription factors could take place in the regulatory region of memory-related genes. Additional investigation is needed to explore with more detail the role of NFAT in neural plasticity and memory.

On the basis of the present findings, we propose a working model for the role of transcriptional regulation in memory reprocessing after retrieval (Fig. 8). The initial process of transcriptional activation induced by retrieval would be mediated by protein kinases. In particular, the activation of IKK $(\mathrm{I} \kappa \mathrm{B}$ protein kinase) induces NF- $\kappa \mathrm{B}$ translocation to the nucleus and its activation. However, prolonged reexposure to the training context induces activation of the protein phosphatase $\mathrm{CaN}$ that blocks NF- $\kappa \mathrm{B}$ activation, as occurs in other systems (Pons and Torres-Aleman, 2000), and induces NFAT translocation and activation. This creates a determinative switch in transcriptional regulation that changes gene expression from that required for memory restabilization to that required for memory extinction. $\mathrm{Ca}^{2+}$-dependent kinases and phosphatases actively control neuronal processing by a tightly regulated balance in which they oppose each other. In this balance, the primary function of $\mathrm{CaN}$ is to negatively modulate neural plasticity (Mansuy, 2003), as in long-term depression (Lisman, 2001). During extinction, the activation of $\mathrm{CaN}$ and NFAT by prolonged exposure to the training context might be attributable to $\mathrm{Ca}^{2+}$ signals that would promote the temporary waning of the original memory trace in the hippocampus. In most cases, extinction is less persistent than the original memory, a fact that allows for spontaneous recovery of the original memory trace. Because gene expression, regulated by transcription factors such as NF- $\kappa \mathrm{B}$, is necessary for long-lasting neural plasticity, inhibition of these transcription factors and activation of others, such as NFAT during extinction, could explain, in part, the less persistent nature of extinction memory.

The role of the hippocampus in fear memory extinction is not as well understood as the role of other neural structures such as amygdala and prefrontal cortex (Maren and Quirk, 2004). For example, contradictory results were reported using hippocampal injections of protein synthesis inhibitors (Vianna et al., 2003; Fischer et al., 2004). Here, the inhibition of molecular processes that regulate gene expression in the hippocampus either improved or impaired extinction, supporting the fact that gene expression in this neural structure is also involved in extinction. Such involvement would be restricted to contextual stimuli because we found no effect of NF- $\kappa \mathrm{B}, \mathrm{CaN}$, or NFAT hippocampal inhibition on cued fear memory. Recent studies also support a critical role of the hippocampus in extinction of contextual fear conditioning, involving other mechanisms such as actin rearrangement (Fischer et al., 2004), action of endocannabinoids through $\mathrm{CB}_{1}$ receptors (de Oliveira Alvares et al., 2008), protein degradation by the proteasome system (Lee et al., 2008), cdk5 signaling (Sananbenesi et al., 2007), and Fyn tyrosine kinase (Isosaka et al., 2009) activation.

The competing nature of reconsolidation and extinction had been previously investigated by means of protein synthesis inhibitors. In contextual memories, the inhibition of protein synthesis shortly before or after a brief reexposure to the context disrupts reactivated memory. Conversely, administration of translation inhibitors in prolonged reexposure impairs extinction, leaving the original memory unaffected (Pedreira and Maldonado, 2003; Suzuki et al., 2004). A model that could enable the understanding of the dichotomous nature of reconsolidation and extinction has been proposed. This model suggests CS offset as a critical signal that determines both the unreinforced presentation and the duration of the CS, which will define the memory course (Pedreira and Maldonado, 2003; Pedreira et al., 2004). The results obtained in the present study agree with that model on the point that the 
activation and translocation of NF- $\kappa \mathrm{B}$ in reconsolidation was observed 15 min after CS offset and CaN and NFAT translocation in extinction was found $45 \mathrm{~min}$ after CS offset. In agreement with the CS offset model is also our finding that no changes in NF- $\kappa \mathrm{B}$ activity were found during the $30 \mathrm{~min}$ of extinction (Fig. $4 b$ ). Thus, the mechanism of NF- $\kappa \mathrm{B}$ activation in reconsolidation, or $\mathrm{CaN}$ activation in extinction and the consequent NF- $\kappa \mathrm{B}$ block and NFAT nuclear translocation, could be initiated after animal remotion from the training context, when the unreinforced presentation and duration of the CS is verified. Nevertheless, it is important to consider the role of ongoing mechanisms that are induced during CS exposure before CS offset, as described in previous reports (Lin et al., 2003b; Fischer et al., 2004; Merlo and Romano, 2008).

Taken as a whole, the experimental data presented here provide new insights into the transcriptional mechanisms underlying memory reconsolidation and extinction. The precise molecular characterization of memory reprocessing after retrieval is relevant for understanding memory dynamics, and to identify novel molecular targets for more effective pharmacological treatments of maladaptive fear memory disorders.

\section{References}

Albensi BC, Mattson MP (2000) Evidence for the involvement of TNF and NF-kappaB in hippocampal synaptic plasticity. Synapse 35:151-159.

Alberini CM (2009) Transcription factors in long-term memory and synaptic plasticity. Physiol Rev 89:121-145.

Baumgärtel K, Genoux D, Welzl H, Tweedie-Cullen RY, Koshibu K, Livingstone-Zatchej M, Mamie C, Mansuy IM (2008) Control of the establishment of aversive memory by calcineurin and Zif268. Nat Neurosci 11:572-578.

Biswas G, Anandatheerthavarada HK, Zaidi M, Avadhani NG (2003) Mitochondria to nucleus stress signaling: a distinctive mechanism of NFkap$\mathrm{paB} / \mathrm{Rel}$ activation through calcineurin-mediated inactivation of IkappaBbeta. J Cell Biol 161:507-519.

Boccia M, Freudenthal R, Blake M, de la Fuente V, Acosta G, Baratti C, Romano A (2007) Activation of hippocampal nuclear factor- $\kappa$ B by retrieval is required for memory reconsolidation. J Neurosci 27:13436-13445.

Casolaro V, Georas SN, Song Z, Zubkoff ID, Abdulkadir SA, Thanos D, Ono SJ (1995) Inhibition of NF-AT-dependent transcription by NF- $\kappa$ B: implications for differential gene expression in T helper cell subsets. Proc Natl Acad Sci U S A 92:11623-11627.

Chytil M, Verdine GL (1996) The Rel family of eukaryotic transcription factors. Curr Opin Struct Biol 6:91-100.

de Oliveira Alvares L, Pasqualini Genro B, Diehl F, Molina VA, Quillfeldt JA (2008) Opposite action of hippocampal CB1 receptors in memory reconsolidation and extinction. Neuroscience 154:1648-1655.

Dudai Y, Eisenberg M (2004) Rites of passage of the engram: reconsolidation and the lingering consolidation hypothesis. Neuron 44:93-100.

Duvarci S, Mamou CB, Nader K (2006) Extinction is not a sufficient condition to prevent fear memories from undergoing reconsolidation in the basolateral amygdala. Eur J Neurosci 24:249-260.

Fischer A, Sananbenesi F, Schrick C, Spiess J, Radulovic J (2004) Distinct roles of hippocampal de novo protein synthesis and actin rearrangement in extinction of contextual fear. J Neurosci 24:1962-1966.

Franklin KBJ, Paxinos G (2001) The mouse brain in stereotaxic coordinates. London: Academic.

Freudenthal R, Romano A (2000) Participation of Rel/NF-kappaB transcription factors in long-term memory in the crab Chasmagnathus. Brain Res 855:274-281.

Freudenthal R, Boccia MM, Acosta GB, Blake MG, Merlo E, Baratti CM, Romano A (2005) NF-kappaB transcription factor is required for inhibitory avoidance long-term memory in mice. Eur J Neurosci 21: 2845-2852.

Genoux D, Haditsch U, Knobloch M, Michalon A, Storm D, Mansuy IM (2002) Protein phosphatase 1 is a molecular constraint on learning and memory. Nature 418:970-975.

Glowinski J, Iversen LL (1966) Regional studies of catecholamines in the rat brain. I. The disposition of $\left[{ }^{3} \mathrm{H}\right]$ norepinephrine, $\left[{ }^{3} \mathrm{H}\right]$ dopamine and $\left[{ }^{3} \mathrm{H}\right]$ dopa in various regions of the brain. J Neurochem 13:655-669.

Graef IA, Mermelstein PG, Stankunas K, Neilson JR, Deisseroth K, Tsien RW, Crabtree GR (1999) L-type calcium channels and GSK-3 regulate the activity of NF-ATc4 in hippocampal neurons. Nature 401:703-708.

Groth RD, Mermelstein PG (2003) Brain-derived neurotrophic factor activation of NFAT (nuclear factor of activated T-cells)-dependent transcription: a role for the transcription factor NFATc4 in neurotrophin-mediated gene expression. J Neurosci 23:8125-8134.

Groth RD, Coicou LG, Mermelstein PG, Seybold VS (2007) Neurotrophin activation of NFAT-dependent transcription contributes to the regulation of pro-nociceptive genes. J Neurochem 102:1162-1174.

Havekes R, Nijholt IM, Visser AK, Eisel UL, Van der Zee EA (2008) Transgenic inhibition of neuronal calcineurin activity in the forebrain facilitates fear conditioning, but inhibits the extinction of contextual fear memories. Neurobiol Learn Mem 89:595-598.

Isosaka T, Kida S, Kohno T, Hattori K, Yuasa S (2009) Hippocampal Fyn activity regulates extinction of contextual fear. Neuroreport 20:14611465 .

Kida S, Josselyn SA, Peña de Ortiz S, Kogan JH, Chevere I, Masushige S, Silva AJ (2002) CREB required for the stability of new and reactivated fear memories. Nat Neurosci 5:348-355.

Lattal KM, Abel T (2004) Behavioral impairments caused by injections of the protein synthesis inhibitor anisomycin after contextual retrieval reverse with time. Proc Natl Acad Sci U S A 101:4667-4672.

Lattal KM, Radulovic J, Lukowiak K (2006) Extinction: [corrected] does it or doesn't it? The requirement of altered gene activity and new protein synthesis. Biol Psychiatry 60:344-351.

Ledgerwood L, Richardson R, Cranney J (2004) D-Cycloserine and the facilitation of extinction of conditioned fear: consequences for reinstatement. Behav Neurosci 118:505-513.

Ledgerwood L, Richardson R, Cranney J (2005) D-Cycloserine facilitates extinction of learned fear: effects on reacquisition and generalized extinction. Biol Psychiatry 57:841-847.

Lee JL, Everitt BJ, Thomas KL (2004) Independent cellular processes for hippocampal memory consolidation and reconsolidation. Science 304:839-843.

Lee SH, Choi JH, Lee N, Lee HR, Kim JI, Yu NK, Choi SL, Lee SH, Kim H, Kaang BK (2008) Synaptic protein degradation underlies destabilization of retrieved fear memory. Science 319:1253-1256.

Lin CH, Yeh SH, Leu TH, Chang WC, Wang ST, Gean PW (2003a) Identification of calcineurin as a key signal in the extinction of fear memory. J Neurosci 23:1574-1579.

Lin CH, Yeh SH, Lu HY, Gean PW (2003b) The similarities and diversities of signal pathways leading to consolidation of conditioning and consolidation of extinction of fear memory. J Neurosci 23:8310-8317.

Lisman JE (2001) Three $\mathrm{Ca}^{2+}$ levels affect plasticity differently: the LTP zone, the LTD zone and no man's land. J Physiol 532:285.

Lubin FD, Sweatt JD (2007) The IkappaB kinase regulates chromatin structure during reconsolidation of conditioned fear memories. Neuron 55:942-957.

Mamiya N, Fukushima H, Suzuki A, Matsuyama Z, Homma S, Frankland PW, Kida S (2009) Brain region-specific gene expression activation required for reconsolidation and extinction of contextual fear memory. J Neurosci 29:402-413.

Mansuy IM (2003) Calcineurin in memory and bidirectional plasticity. Biochem Biophys Res Commun 311:1195-1208.

Maren S, Quirk GJ (2004) Neuronal signalling of fear memory. Nat Rev Neurosci 5:844-852.

Marsicano G, Wotjak CT, Azad SC, Bisogno T, Rammes G, Cascio MG, Hermann H, Tang J, Hofmann C, Zieglgänsberger W, Di Marzo V, Lutz B (2002) The endogenous cannabinoid system controls extinction of aversive memories. Nature 418:530-534.

Meffert MK, Chang JM, Wiltgen BJ, Fanselow MS, Baltimore D (2003) NFkappa B functions in synaptic signaling and behavior. Nat Neurosci 6:1072-1078.

Merlo E, Romano A (2008) Memory extinction entails the inhibition of the transcription factor NF-kappaB. PLoS One 3:e3687.

Merlo E, Freudenthal R, Maldonado H, Romano A (2005) Activation of the transcription factor NF-kappaB by retrieval is required for long-term memory reconsolidation. Learn Mem 12:23-29.

Milekic MH, Pollonini G, Alberini CM (2007) Temporal requirement of 
$\mathrm{C} / \mathrm{EBPb}$ ta in the amygdala following reactivation but not acquisition of inhibitory avoidance. Learn Mem 14:504-511.

Miller CA, Marshall JF (2005) Molecular substrates for retrieval and reconsolidation of cocaine-associated contextual memory. Neuron 47: 873-884.

Nader K, Schafe GE, Le Doux JE (2000) Fear memories require protein synthesis in the amygdala for reconsolidation after retrieval. Nature 406:722-726.

Noguchi H, Matsushita M, Okitsu T, Moriwaki A, Tomizawa K, Kang S, Li ST, Kobayashi N, Matsumoto S, Tanaka K, Tanaka N, Matsui H (2004) A new cell-permeable peptide allows successful allogeneic islet transplantation in mice. Nat Med 10:305-309.

Pedreira ME, Maldonado H (2003) Protein synthesis subserves reconsolidation or extinction depending on reminder duration. Neuron 38:863-869.

Pedreira ME, Pérez-Cuesta LM, Maldonado H (2004) Mismatch between what is expected and what actually occurs triggers memory reconsolidation or extinction. Learn Mem 11:579-585.

Phillips RG, LeDoux JE (1992) Differential contribution of amygdala and hippocampus to cued and contextual fear conditioning. Behav Neurosci 106:274-285.

Pons S, Torres-Aleman I (2000) Insulin-like growth factor-I stimulates de- phosphorylation of $\mathrm{I} \kappa \mathrm{B}$ through the serine phosphatase calcineurin (protein phosphatase 2B). J Biol Chem 275:38620-38625.

Rescorla RA (2004) Spontaneous recovery. Learn Mem 11:501-509.

Romano A, Freudenthal R, Merlo E, Routtenberg A (2006) Evolutionarilyconserved role of the NF-kappaB transcription factor in neural plasticity and memory. Eur J Neurosci 24:1507-1516.

Sananbenesi F, Fischer A, Wang X, Schrick C, Neve R, Radulovic J, Tsai LH (2007) A hippocampal Cdk5 pathway regulates extinction of contextual fear. Nat Neurosci 10:1012-1019.

Sugiura R, Sio SO, Shuntoh H, Kuno T (2001) Molecular genetic analysis of the calcineurin signaling pathways. Cell Mol Life Sci 58:278-288.

Suzuki A, Josselyn SA, Frankland PW, Masushige S, Silva AJ, Kida S (2004) Memory reconsolidation and extinction have distinct temporal and biochemical signatures. J Neurosci 24:4787-4795.

Vashishta A, Habas A, Pruunsild P, Zheng JJ, Timmusk T, Hetman M (2009) Nuclear factor of activated T-cells isoform c4 (NFATc4/NFAT3) as a mediator of antiapoptotic transcription in NMDA receptor-stimulated cortical neurons. J Neurosci 29:15331-15340.

Vianna MR, Igaz LM, Coitinho AS, Medina JH, Izquierdo I (2003) Memory extinction requires gene expression in rat hippocampus. Neurobiol Learn Mem 79:199-203. 